\section{¿Cómo sería todo antes de la luz eléctrica?}

por Francesco di Girólamo

Oxido de hierro para el rojo.

Carbón y dióxido de manganeso para el negro.

Oscuridad total. Puntos de luz en movimiento. Bordes siempre oscilantes.

Sería por eso que los grandes mosaicos bizantinos perfilaban sus figuras con una línea negra y las suspendían siempre sobre un campo de oro?

A la luz de las antorchas y los cantos gregorianos deben haber oscilado sin parar...

La imprecisión como un valor a completar por el que mira.

La luz es una oscilación.

La luz es una composición percibida.

El color es una particular frecuencia de la luz visible y cada color es una oscilación particular: Una descarga de energía hace "saltar" los electrones a otro estado y la energía que "pierde" la libera como color. El color es una diferencia de energía percibida de manera única por un receptor. La visión es un sistema.

La realidad es un sistema.

La representación es un sistema.

Los paradigmas que permanecían y permitían construir a partir de que el mundo era estable y que permanecería allí el tiempo suficiente para poder amarlo, se han ido para siempre. El "principio de incertidumbre" de Heiselberg, que planteaba la imposibilidad de fijar la velocidad y la posición al mismo tiempo, fue una especie de anuncio de lo que se ha instaurado como habitual... la ciudad, el ámbito y la cultura no paran de cambiar. La frontera entre Certeza e Incertidumbre se curva y se escapa como la velocidad de la luz... no hay tal cosa como un punto fijo e inamovible, hoy.

Representación. "En la representación extática, se reflejaba la inmutabilidad del ideal de comportamiento."

Ante la nitidez o el "todo a foco" del Renacimiento, Leonardo inventa los "no bordes", el extremo difuso, la absoluta fluidez. Todo forma parte un poco de todo.

Esto se ve claramente en el estudio que hace Leonardo dibujando la perspectiva para la "Adoración de los Magos", que claramente es un pretexto: el asunto es la superposición del cálculo con la expresión.

Este ES EL PROBLEMA DE DISEÑO A RESOLVER.

Nosotros, profesionales y docentes que venimos de un mundo lineal, que construyó y midió el tiempo y la historia de modo lineal, que ordena los discursos y las explicaciones del mundo de manera lineal, nos vemos enfrentados a nuevas explicaciones sin forma ni estructura definida, menos asibles, mas interpretables. Nos enfrentamos a sistemas de trabajo y respuesta que involucran más y menos precisas variantes, con mayor grado de improvisación y a distintos modos no previstos de respuestas formales.

Es como si el intento de James Joyce en Ulises, cuando elimina la puntuación y mezcla el tiempo, se hubiera hecho realidad.

Dan cuenta de esto la Bienales, los trabajos en Arquitectura Genética, los espacios expositivos digitales, la microbiologia y los motores miológicos, los estudiantes digitales de hoy consultando todo a la $\mathrm{vez}$, las presentaciones multisoportes herederas de las instalaciones de Joseph Beuys... en que la inteligencia que las describe toma la dirección impensada y uno debe aprender a mirar de nuevo.

\section{(Memo Atkien)}

¿Cómo producir material innovador para la generación de productos irrepetibles para la competencia?

Material. Tecnología. Legislación.

Diseñar diversamente para producir en un modo diverso implica necesariamente que el acercamiento al problema de diseño es el que debe cambiar.

"El Barroco no remite a una esencia, sino más bien a una función

operatoria, a un rasgo.

No cesa de hacer pliegues.

No inventa la cosa: ya había todos los pliegues procedentes de ori- 
ente, los pliegues romanos, griegos, románicos, góticos, clásicos... Pero él curva y recurva los pliegues, los lleva hasta el infinito, pliegue sobre pliegue."

Gilles Deleuze.

Hoy no es presentable producir desechos.

Se diseña para el desarmado al final de una vida útil. La reutilización Es el diseño.

Dejar las partes, ensamblajes, encajes, en evidencia. La personalización es la descomposición. El No des-hecho es el cálculo del diseño.

¡Hoy hay entre diez mil y treinta mil especies vivientes menos al año! Se consume cuatro veces más que lo que produce la tierra.

El $80 \%$ del impacto ambiental de un objeto se decide en la etapa inicial del diseño.

$¿ 80 \%$ de desecho para un celular de 150 gr?

Entonces lo fácilmente y bellamente separable es parte de una nueva y diferente manera de encarar el diseño del entorno, su equipamiento y su rápida variabilidad morfológica y práctica.

Reusar más que reciclar. El proceso es un proyecto de diseño en sí mismo. Las posibilidades de lo nuevo en un nuevo escenario que tiene que ver con el uso del material en un modo inteligente, simple y eficiente.

El ciudadano de hoy atraviesa apuradamente "escenografías" entre su casa y su trabajo, entre el colegio y la casa, la universidad y la casa o lo que sea que tenga que hacer. La ciudad se ha reducido a un escenario móvil que se desliza entre puntos más o menos habituales dentro de "nuestro" Santiago... ¿dónde ha quedado el ciudadano? Aparece en ciertos espacios conectores, bien diseñados, más íntimos, más próximos e integrados, a escala humana, en ciertos suelos equipados que entran y salen de los lugares albergando el paseo y el vitrineo, el consumo y la conversación, el estar al abrigo entre los otros.

Se trata también de la movilidad y la liberación de los espacios. En la liberación de los suelos está la nueva y afiancada concepción de que lo mejor ya no es lo más pesado. Se diseñan nuevos materiales que ya no son un remedo "de" sino que tienen morfologías y apariencias propias, que renuevan el paisaje urbano. La relación entre uso y consumo debemos repensarla. Por ejemplo, si cosas como una cocina se pudieran armar por pedidos y requerimientos específicos, y luego se usaran por un tiempo determinado, para luego volver a la fábrica para ser desarmadas a la espera de un nuevo pedido de ensamblaje, sería una manera increíble de evitar el desecho de "totales". Solo se necesitaría cambiar piezas defectuosas para rearmar en vez de reciclar. Personalización del diseño.

Piezas desarmables. La reducción del volumen del producto. Embalaje y transporte. Cantidades.

Un criterio de lo "no sobrante". No generar sobras. No pretender que todo se puede hacer de nuevo cada vez. ¿Es necesario seguir creciendo cada vez a un ritmo mayor, generando cada vez más desechos bajo la excusa de no desemplear a grandes cantidades de gente?

El diseño debiera poder resolver esto. ¿Qué significa el diseño de productos hoy? El diseñador debe ser poliédrico, múltiple. Debe pensar y diseñar para un mercado que aún no existe, mientras se mueve en un ambiente altamente mutable, la destrucción de las nociones de frontera y localidad, debido a la velocidad y flujos de las redes de información y comunicación.

El imaginario hoy es un flujo y no lo inmutable, con lo cual se interactúa sin filtros y sin antecedentes. Desde la pieza se accede aleatoria y fragmentadamente a lo que se quiere ver/consultar. Es tal el incesante flujo de información visual y multicultural, que llega fragmentada vía red, cine y TV principalmente, que está alterando -yo diría para siempre- y sobre todo en los jóvenes, el concepto de pertenencia y patrimonio continental y local. Por otro lado, este flujo imparable de visiones increíbles de las formas del mundo en todos los ámbitos nos está entregando constantemente reformulaciones formales y técnicas a los diseñadores de todo el orbe, independientemente de la escuela donde estudien y de los medios que tengan. El asunto está en que nos preguntemos en las escuelas de diseño, cómo podemos transformar este tremendo caudal de información, en conocimiento y en aplicaciones locales innovadoras y pertinentes, que enriquezcan nuestro entorno cotidiano y nuestras ganas de vivir más que ser soluciones fashion per se.

Cada vez hay más altos niveles de interacción

En esta fragmentación de la información, adquiere una importancia enorme la connotación. Son las cuestiones semánticas las que generan las decisiones que "conectan" las tecnologías. Surgimiento del campo formal desde una suerte de poética que busca algún modo, alguna gestualidad para cubrirlo, para dar con la morfología. Por ejemplo, 
los grandes paneles de hormigón negro cuya geometría fue diseñada/ definida a partir de la acústica. La impresión de una onda y secuencia particular en el proceso de fraguado/diseño del material, en el Museo Nacional de Australia. Geometrías a partir de la acústica.

Connotación, modernidad y patrimonio. Pareciera que el patrimonio tiene que ver con una toma de conciencia de los ciudadanos sobre las cosas que permanecen para que nosotros hablemos de ellas a los que vienen. Patrimonio es lo que nos da el sentimiento de pertenencia afectivo al lugar donde nacimos y crecimos, vinculando las construcciones, los objetos, los entornos, al recuerdo y al contexto, generando una suerte de memoria colectiva.

Lo patrimonial es la huella incompleta de un pasado compartido, esplendoroso o no, a través de la cual intentamos acercarnos a ese momento para mirarlo entre la niebla. Esas huellas están diseminadas en tiempo y lugar, y por ello el intento es finalmente ecléctico e interpretativo. ¿Cuáles son las huellas que estamos construyendo para el futuro global cuyo concepto de nación se encuentra cada vez más diluido?

Tecnologías que no compliquen al usuario. Diseño de fases de interacción con visualidades y mensajes claros. Las dimensiones poéticas del diseño permiten crear nuevas operaciones formales para una visualidad diferente y contemporánea. ¡No más clepsidras para indicar el paso del tiempo en un computador de última generación!

El diseño debe ser un medio para educar sobre el entorno y el ámbito de vida en el que nos queremos desenvolver. Hemos llegado a una especie de sobrediseño casi imposible de digerir, donde la tendencia y la última moda en decoración implican unos espacios indeterminados con sabor a casa piloto... a catálogo de última hora.

La construcción de un doble frente continuo en Puerto Madero, de altura homogénea respecto de la línea de las antiguas bodegas de ladrillo recuperadas, resplandeciente de acero, aluminio y vidrio, espejeándose las dos orillas a través del espacio aéreo/acuático de los diques.

Reinvención y reinterpretación acertada del entorno en el cual se insertan los cambios, a partir de una operación inicial que efectivamente logra decidir un escenario en conjunto, "en ronda" dirían otros.

\section{Lo coincidente}

"El título de un libro de poemas es muy importante, porque debe ser una síntesis de contenido y forma. Buscar un título es como escribir el más largo y más difícil de mis poemas. Para hacerlo no opero con la inteligencia, como operaría para buscar un lápiz perdido, por ejemplo, sino que trato de conseguir un estado de ánimo propicio para que acudan y se combinen las imágenes poéticas. Después, someto a esas imágenes a una crítica...”

Nicanor Parra. Entrevista El Mercurio.

Hoy se vive inmerso en la complejidad. El concepto de complejidad es un hecho inherente a la proyección de algo, asociado al concepto de contradicción.

Las redes y los entrecruzamientos están en todas las escalas, especialmente en el hábito cada ve más adquirido de las conexiones múltiples simultáneas: Ipad, Iphone, Facebook, Tumblr, Twitter, whatsapp... una estructura sostenida en diversas plataformas gratuitas de contenido no coherente. Todo a la vez.

Finalmente, pareciera que nadie está donde está porque está pendiente de no perderse "otra cosa”. Por ello lo simultáneo acarrea algo que podemos llamar Lo impreciso. Y lo impreciso es un riesgo.

"No estoy seguro de que el chileno, en primer lugar, esté dispuesto a tomar riesgos de fracaso. Para ser empresario hay que fracasar. Es como tratar de aprender esquí pero que sea una vergüenza caerse. Si tú no te puedes caer esquiando, no puedes aprender a esquiar. Y si tú no puedes fracasar con tu emprendimiento, no puedes aprender a ser emprendedor. Esa es una cosa clave."

Agustín Hunneus. Empresario vitivinicola en entrevista a Revista El Sábado.

Incursionar en un momento en que la obra se disgrega en varias plataformas, sustratos, formatos y soportes: videos, trailers, making off, web, blogs, impresos, iphones... imágenes de imágenes al instante en la mano: ¿Una pintura en un Iphone es una pintura? La reformulación del enfrentamiento con la obra cuando se accede a la visualización a través de la inmediata reproducción.

Todo son obras en permanente construcción y manipulación y modificación de formato, sentido y propósito. El registro del proceso es la sintonía con el medio. Las formas de la presentación toman una nueva visualidad, que en su conjunto conforman un nuevo concepto de "obra”. Una suerte de Hyper Design a través de la exploración de las infografías visuales de generación y difusión. Cuadros, planos, tiempos de exposición, secuencias y expresión. Fijación y movimiento del que hacer. Joshua Davis dice que siempre hay que estar atento a donde se producen los "accidentes" en la obra, y rescatarlos para 
El campo del diseño es un campo intelectual, donde a través de la mirada y la inteligencia se rescatan cosas para integrarlas a un flujo de trabajo. ¿Qué se le hace a lo que se trae? ¿Basta con traer algo? Recoger y guardar todo. Establecer la cultura de lo "no obsoleto". Fomentar la curiosidad.

- "A veces pienso que todo eso fue para mí" - dijo Baradit.

- "Es una manera de verlo" - dije yo.

Quizás a la manera de que una tipografía es la forma visual del sonido, la figura de una cierta presencia o personalidad inherente a las cosas que se nombran o que se quieren transmitir. La intuición y luego la investigación. El dar forma es un proceso que se reviste de sí mismo a través de la búsqueda. Luego, generalmente lo hallado altera totalmente el plan inicial (Picasso, Braque, rauschenberg). En la tipografía, el asunto está en las ligaduras, es lo que hace Andreu Balius CON CARMEN O CZESKA.

Rediseño. Antecedentes. Citas. Referentes.

Cambio de escala en la profundidad y en la forma.

De un croquis al afiche gigante: el cambio de escala que revela otra mirada en lo público. Lo público tiene otra mirada. El impacto a las personas.

El cambio de mundo como alteración de una visión, de un cierto tipo de visión.

Alteración de la visualidad a través de un lenguaje particular.

El diseño se ocupa de las cosas que existen. Las analiza, y a esa mirada le busca un concepto. Le pone nombre para aplicarlo a un contexto. ¿Qué es un concepto particular? ¿Qué necesita un contexto particular? ¿Cómo aparecer?

Rediseño del concepto existente no por la novedad sino por la innovación.

\section{Insistencia.}

Grados y escalas de esa insistencia.

El sostenimiento de esa insistencia en el tiempo.

Diseño y permanencia.

Hay una variable tiempo y hay una variable espacio y contexto. Las ideas necesitan un tiempo a la espera de un contexto adecuado. Algo. Alguna posibilidad se ha entrevisto pero hay que dar con los aspectos que permiten que esto aparezca. Hay que reunir y hay que juntar.

Hay que ver qué resiste y qué permanece. Datos los flijos y la inmensa variabilidad y rapidez de los cambios y comportamiento del medio, para que algo perdure debe modificarse alrededor de un concepto central.

El sentido del diseño, finalmente tiene que ver con cierta calidad de la morfología cultural del mundo. No para llamar la atención en el aspecto del espectáculo o la novedad, sino en el sentido del rediseño de las posibilidades del mundo, o de lo que llamamos mundo.

El rediseño es la fuente de la innovación, a través del desarrollo del proyecto.

¿Cómo ser conscientes de todo el proceso? El contexto es parte de la invención del tiempo de proyecto como la primera parte del propio emprendimiento. Nadie lo hará por él.

Retroalimentación. La alimentación y el empuje generalmente vienen de otro campo, de otro ámbito de desempeño. Por ello el diseño no es un trabajo a la manera de la obtención de "un puesto de trabajo”. Es una obsesión, una especie de coleccionismo, una pasión de mirar y transformar porque se ha visto una posibilidad.

¿Cómo apropiarse de lo intangible para darle una visualidad?

El diseño es un trabajo de aproximación, no de exactitud.

Es una suerte de construcción a partir de una paisaje mental vinculado a la cultura.

El medio es el mensaje... o el proceso de desarrollo es el diseño.

La puesta en valor del registro de la secuencia en el tiempo que ha hecho posible la aparición de un proyecto, hoy se reconoce como inherente a la existencia de una obra, antes de su configuración final como objeto o producto. Incluso algunos afirman que ese proceso es la obra. Pareciera que es en este proceso donde aparece en plenitud, en palabras de Peter Eisenmann, "la presencia visible de la estructura conceptual o profunda”. El asunto es que el diseño por sí solo no comunica las intenciones del diseñador.

Lo único que puede dar cuenta de esto y dar a conocer o explicitar las ideas y el trabajo de diseño, es un registro del proceso de diseño.

Una cierta estratificación o catalogación de los hallazgos.

Bagaje y diseño construyen un orden.

Connotación.

Poner orden en una propuesta "atonal" a la manera de los dodecafónicos. 
Lo atonal no es la novedad, no es el gusto masivo, no es la tendencia.

Es una suerte de transgresión a partir de una reformulación.

Transición. Nada se crea de la nada.

Por ello el diseño es con la cultura.

Es dar valor y hacer percibir este valor.

El dar valor es una construcción mental, es una historia, es un cuento que merece ser contado en el desarrollo del diseño, y plasmado en el producto final de ese proceso. Lograr hacer entender por qué algo es especial y proyectarlo en el tiempo.

Crear la historia. Crear los nombres.

Interdisciplinariedad. Fluidez.

El diseñador es un intérprete cultural. Para ello necesita de la colaboración y la fusión con otras disciplinas. El diseñador convoca y conecta realidades que no se tocan y las propone a la manera de "hagamos algo con esto".

Ojos abiertos. El viaje es el destino.

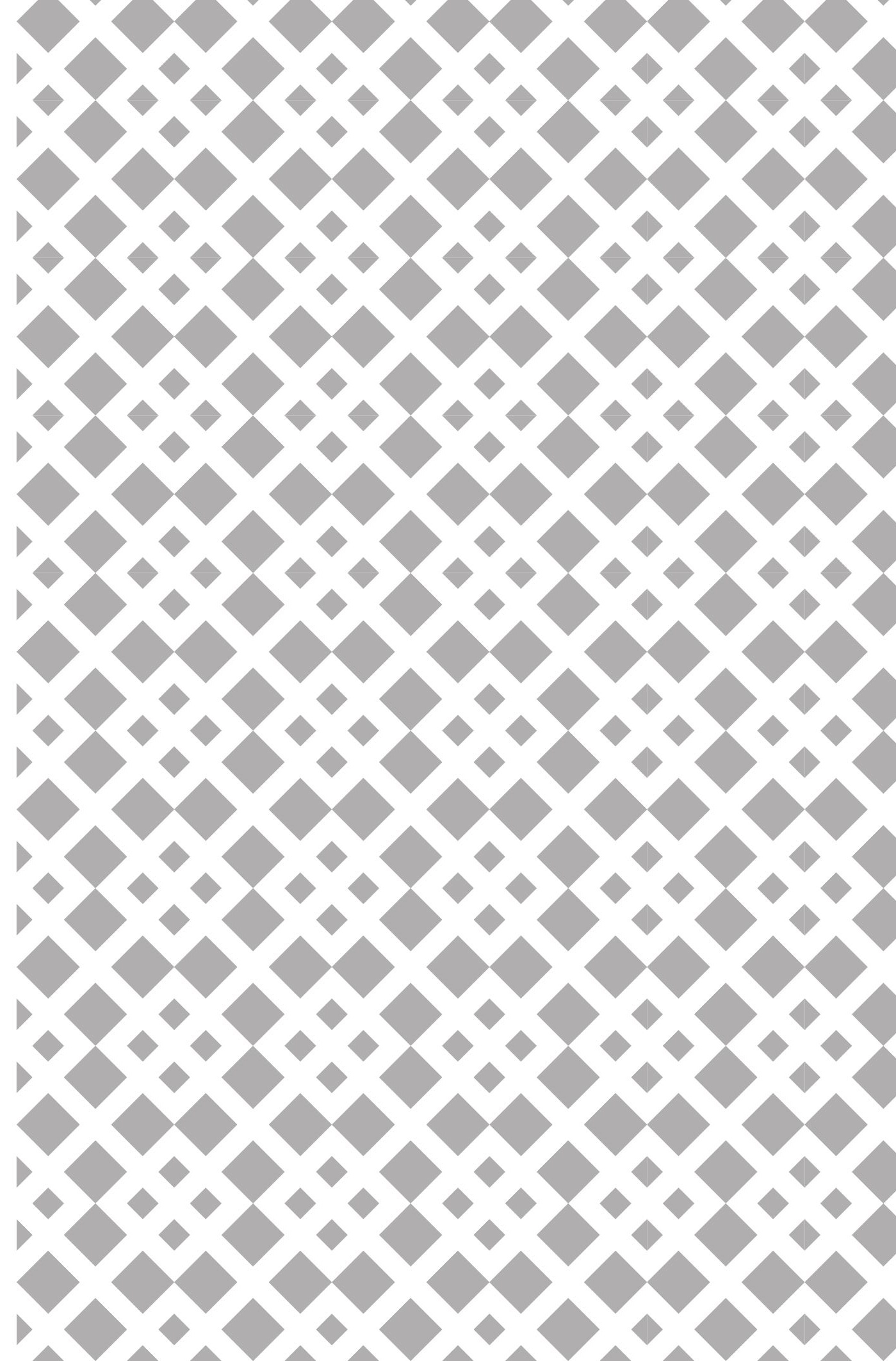

